\title{
Improving performance of roundabout intersections by optimizing traffic-flow speed
}

\author{
Marinela Ință ${ }^{1, *}$ \\ ${ }^{1}$ Lucian Blaga University of Sibiu, Industrial Engineering and Management Department, 550025, \\ Victoriei, 10, Sibiu, Romania
}

\begin{abstract}
Streamlining of urban traffic influence nowadays almost everything about our modern life. The main effect, which we all feel as the daily traffic participants, either as pedestrians or vehicles drivrers, is travel time to work and back. Roundabouts intersections have a number of advantages over intersections with traffic lights, they reduce the severity of accidents, traffic speeds to provide an "calmer" road environment. So, operating performance of roundabouts are complicated, influenced by the confluence operations. The paper aims at analyzing the current situation of traffic in two crowded roundabouts in Sibiu, comparing the results with the original data and proposing solutions to improve traffic conditions and especially traffic speed. The obtained results will be the basis for improving the overall capacity of roundabouts.
\end{abstract}

\section{Introduction}

\subsection{Backgrounds}

Transportation is an important factor in the development of society. Besides transport have a positive impact on economic development, they attract all the negative effects such as pollution of the environment, traffic congestion, accidents, etc.

Sibiu is one of the most prosperous cities in Romania and receives one of the highest rates of foreign investment. Thus, besides the traditional industrial city (engineering industry - Bilstein Compa, clothing industry - Mondostar, food industry - Scandia, after 1995 were created new companies in the field of automotive (Continental, Kuhnke relays, SNR bearings, Takata, Siemens).

With the development of industry, also population grew in Sibiu. As seen in the chart below, Sibiu's population has increased more than 11 times in a period of 163 years since they achieved first statistical data collected in censuses.

With this population growth, increased automatically and their need to travel. So, the number of registered vehicles has increased considerably in Sibiu, plus the ones in transit.

\footnotetext{
${ }^{*}$ Corresponding author: marinela.inta@ulbsibiu.ro
} 


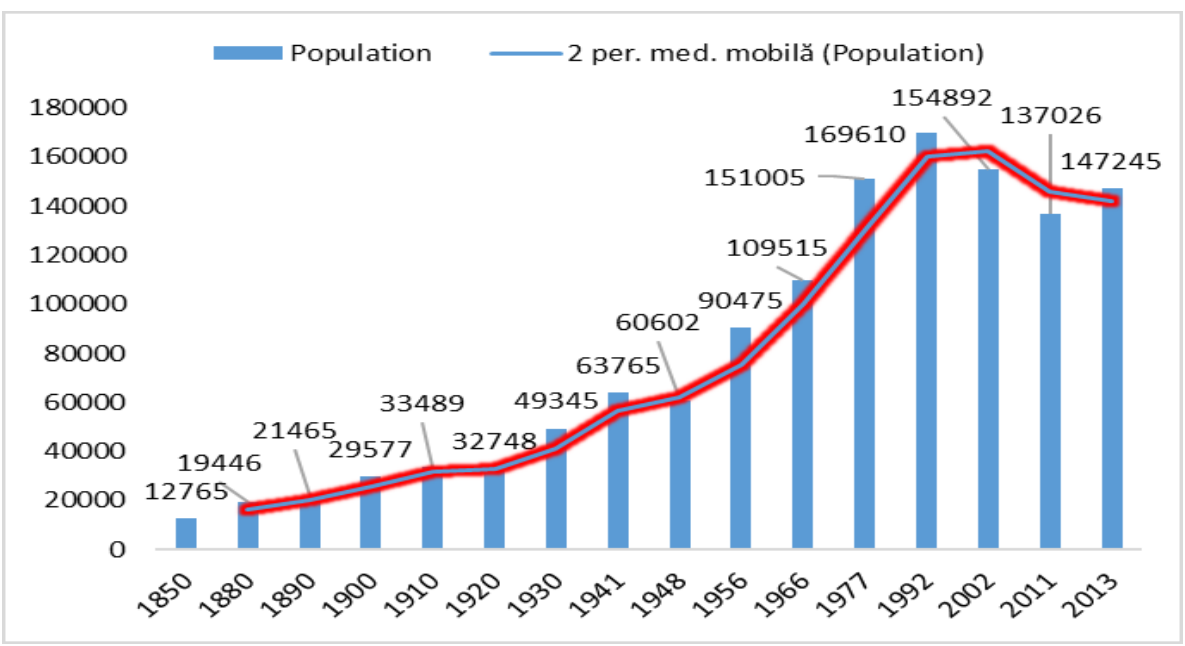

Fig. 1. Evolution of the population of Sibiu

If in 1985 the daily average annual vehicles circulating in Sibiu was 846, in 2010 their number doubled to 1752 , and forecasts show that by 2025 the number of vehicles that will move could increase up to 3254 , according to data provided by the National company of Motorways and National Roads in Romania [1].

\subsection{Historic}

The spread of roundabouts began when British engineers have redesigned circular intersection in mid 1960 and Frank Blackmore invented the mini roundabout to overcome capacity limitations of movement and protection measures [2].

Unlike circular intersections, roundabouts operate with rules to give priority to traffic already in the intersection and the traffic that leaves the intersection and the driver removes much of the confusion associated with circular intersections and waiting time for the drivers to intersections with traffic lights. Having roughly the same size as the intersections marked with the same capacity, roundabouts are significantly smaller in diameter than most circular intersections, separates entering and exiting traffic of the intersection with sites developed for pedestrians to encourage driving at lower speeds.

Sibiu is in full economic development, leading to the development of transport and automaticaly to the emergence of traffic congestion. This can be seen in the peak hours in the central areas and in areas of entry / exit in the city.

One of the main arteries of the city is the road of Alba Iulia that connects the central and western industrial area (exit to Sebes - Alba). This artery is made up of several types of intersections including roundabouts and large flow of vehicles creates problems in terms of fluency, resulting in increased congestion level.

\section{Data collection}

The biggest traffic congestion occurs on the road in the area formed by two roundabouts (Alba Iulia - Autogarii and respectively - Alba Iulia - Maramureșului - Malului). This is due to the following reasons:

- A zone of economic interest (linking with the Western industrial area, along artery are points of interest such as Banca Carpatica, store Lidl, DM, Kaufland, Peny market, gas stations, hotels, restaurants, etc; 
- Main access route to Sibiu International Airport;

- Positioned on both sides of the river Cibin.

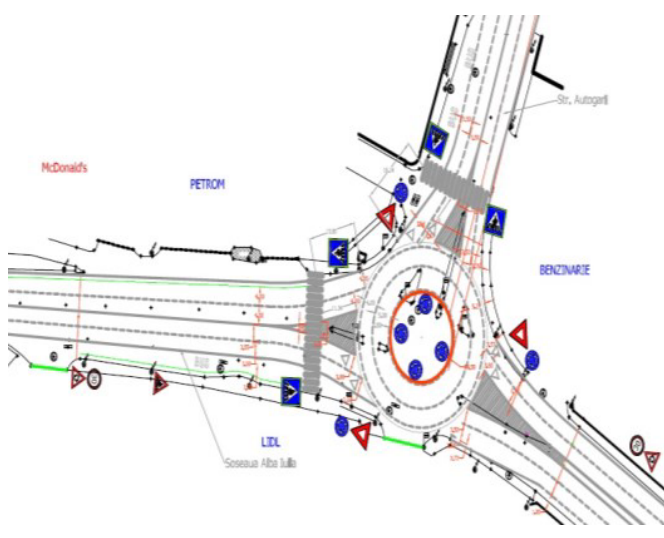

Fig. 2. Alba Iulia - Autogării

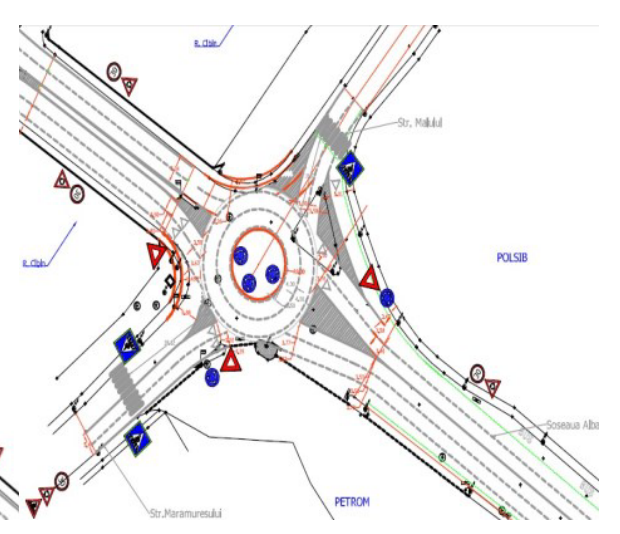

Fig. 3. Alba Iulia - Maramureșului - Malului (source: http://www.sibiu.ro/index.php/primaria )

Table 1. Geometric elements of intersections.

\begin{tabular}{|l|c|c|}
\cline { 2 - 3 } \multicolumn{1}{c|}{} & $\begin{array}{l}\text { Roundabout Alba Iulia - } \\
\text { Autogării }\end{array}$ & $\begin{array}{l}\text { Roundabout Alba Iulia - } \\
\text { Maramureșului - Malului }\end{array}$ \\
\hline Inner radius & $9,5 \mathrm{~m}$ & $8 \mathrm{~m}$ \\
\hline Outer radius & $14,5 \mathrm{~m}$ & $16 \mathrm{~m}$ \\
\hline Number of annular strips & 2 & 2 \\
\hline Width of the annular band & $4-5 \mathrm{~m}$ & $4 \mathrm{~m}$ \\
\hline Entry lanes & 2 lanes on each arm & 2 lane on each arm \\
\hline Entry lanes width & $3,5-4 \mathrm{~m}$ & $3-4 \mathrm{~m}$ \\
\hline
\end{tabular}

Although over time they have made improvements in terms of structure and type of intersection, and today can be seen queues and delays. Queues formed both morning and afternoon when most city residents are going or returning from work or school units, as well as on weekends when they go to supermarkets.

Traffic data were collected using traditional through manual spot counting of vehicles, then counting their record sheets per the category they belong.

These were collected through an observer team during a week to cover variations in traffic. The length of data collection was 15 minutes, three times per day for each junction. Under the traffic data, collection was followed:

- registration number of cars on each band;

- pedestrian traffic record;

- the length of the queue;

- the number of cyclists;

- frequency of the means of public transport.

It was verified that during data collection not appear major errors which, then to affect results because errors can lead to misinterpretations of traffic conditions. Before data collection there were studied the twoo roundabouts to determine the points of maximum visibility to allow observation of all intersection arteries.

Because traffic flows have a variable component, indentificating the vehicles in different categories was used for mixing standard vehicles through equalization coefficients. These coefficients represent the ratio of occupying road space by dynamic physical vehicle and vehicle occupancy standard - equal to unity - that is the car. 
Thus, Figures 4 show the average standard vehicles volumule in the twoo roundabouts (Alba-Iulia- Autogării noted wih R1, Alba Iulia - Maramureșului - Malului noted wih R2) collected during one week.

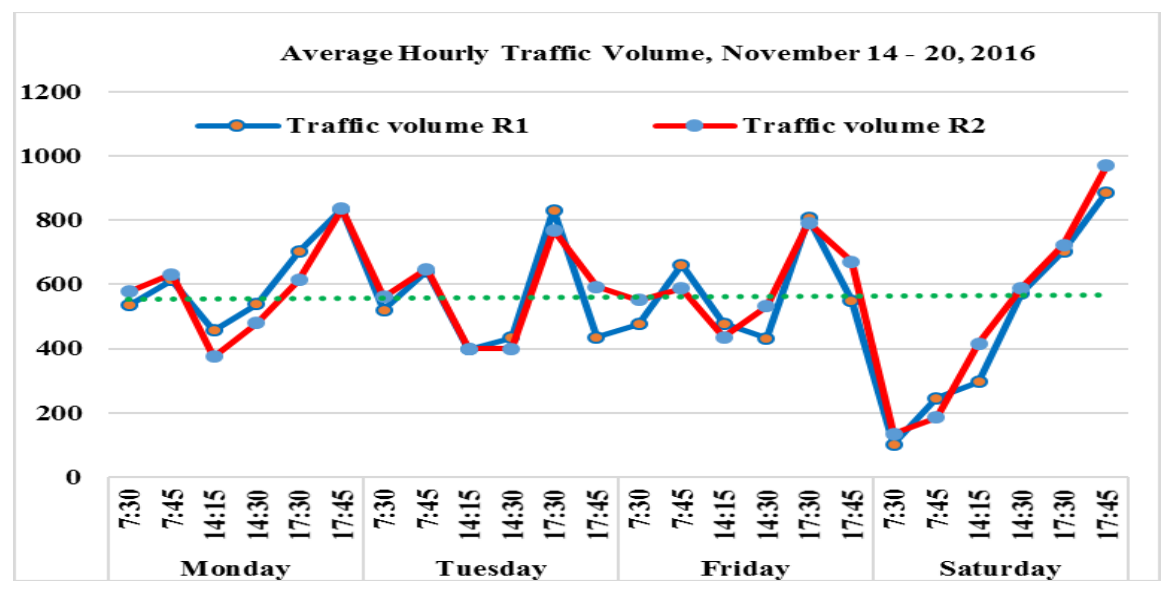

Fig. 4. Hourly and daily distribution of traffic volume data collected for two roundabouts

\section{Traffic Data Analysis and levels of service (LOS)}

After data collection, first were analyzed conflict points for the twoo intersection. Total conflict points of intersection being 33 and 35 respectively, divided into:

- divergence points - 9;

- convergence points - 7;

- crossing points - 17 and 19 respectively ( 7 points known crossing points vehicle - vehicle, 10 crossing points vehicles - pedestrian).

These data were then compiled Microsoft Excel data sheets calculation along with each roundabout, scheme, based on literature formulas were calculated and analyzed average speed on each arm, peak hour factor of each intersection.

\subsection{Road traffic speed}

Velocity is the main parameter of the road, because it characterizes purpose of travel and depends on the technical characteristics of vehicles, road network and capacity of vehicle drivers.

$$
V=\frac{l}{t}[\mathrm{~km} / \mathrm{h}]
$$

where:

$l$ - length of road sector examined;

$t$ - time in which the road was tranzited.

Average travel speed for every roundabout in each direction is shown in the figure below.

The difference between the speed between the three arms is caused by different diameters of the bands and confluence actions [3]. 


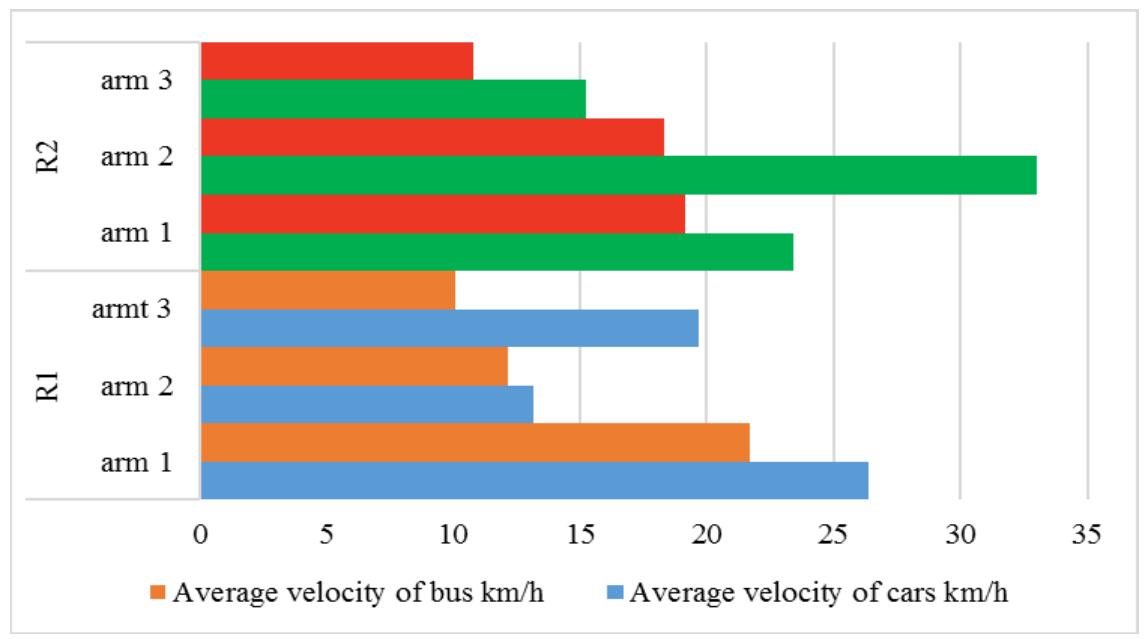

Fig. 5. Average velocity of vehicles $(\mathrm{km} / \mathrm{h})$.

These values indicate that vehicles confluence influences vehicle speed on band 1 . Confluence vehicles have lower speeds because they usually decelerate before entering the roundabout.

\subsection{Peak hour factor (PHF)}

Peak hour factor in urban areas generally range between 0.80 and 0.98 . Values lower than 0.80 means greater variability traffic flow, and values close to 0.98 represents small variations in traffic flows. Peak hour factor over 0.98 indicates a high volume of traffic.

Following application of the formula results for the first roundabout a peak hour factor of 1.23 and respectively 1.07 for the second sense.

To validate values obtained it were modeled and simulated with software Synchro Studio the twoo roundabouts junctions [4]. The sofware displays related reports of: intersection capacity utilization (ICU), level of service (LOS), delays of vehicles, total number of stops, travel time, $\mathrm{HC}, \mathrm{CO}$ and NOx emissions and fuel consumption (Table 2 and Table 3).

Table 2. Str. Alba-Iulia \& Str. Raului Performance by movement

\begin{tabular}{|l|c|c|c|c|c|c|c|c|c|}
\hline Movement & EBL & EBT & EBR & WBL & WBT & WBR & NBL & NBT & NBR \\
\hline Delay / Veh (s) & 13.3 & 14.4 & 15 & 343.7 & 288.4 & 208.7 & 578.3 & 702 & 474.3 \\
\hline Stop/Veh & 0.83 & 0.78 & 0.52 & 1.5 & 1.25 & 2.07 & 0.3 & 0.26 & 0 \\
\hline Avg Speed (kph) & 22 & 21 & 21 & 5 & 4 & 14 & 2 & 2 & 2 \\
\hline Fuel Used (1) & 0.3 & 5.1 & 1 & 2.1 & 7.9 & 2.2 & 2.9 & 4.2 & 0.7 \\
\hline HC Emissions (g) & 0 & 15 & 2 & 0 & 22 & 1 & 5 & 0 & 0 \\
\hline CO Emissions (g) & 11 & 356 & 57 & 43 & 435 & 67 & 103 & 67 & 11 \\
\hline NOx Emissions (g) & 2 & 50 & 7 & 3 & 38 & 7 & 5 & 3 & 0 \\
\hline
\end{tabular}

Following the completion of simulations of roundabouts using the program Synchro Studio, you may notice an ability to use the intersections of over $100 \%$ and a level of service $\mathrm{H}$, therefore helps to create tails (congestion), low level of comfort and increased risk of accidents. 
Table 3. Alba-Iulia \& Str. Autogarii Performance by movement

\begin{tabular}{|l|c|c|c|c|}
\hline Movement & EB & WB & NB & SB \\
\hline Delay / Veh (s) & 3.7 & 6.1 & 11.6 & 21.4 \\
\hline Stop/Veh & 0.27 & 0.29 & 0.67 & 0.65 \\
\hline Avg Speed (kph) & 22 & 27 & 8 & 14 \\
\hline Fuel Used (l) & 3.2 & 2.8 & 0 & 3.7 \\
\hline HC Emissions (g) & 9 & 12 & 0 & 15 \\
\hline CO Emissions (g) & 198 & 279 & 1 & 315 \\
\hline NOx Emissions (g) & 29 & 38 & 0 & 45 \\
\hline
\end{tabular}

$\mathrm{H}$ level of service (LOS H) describes operations with control delays excessive, over 80 seconds to a vehicle. This level is considered unacceptable by most of the drivers, often due to over saturation of traffic that occurs due to excedes traffic capacity of intersections. These delays occur with a ratio V/Q great.

In other words, utilization capacity exceeded intersections and the traffic is not conducted in the normal range. Because the infrastructure does not allow major changes, only improvements that can be made are in the geometry of the intersection, which can have a positive influence on the traffic flow of the twoo roundabouts.

\section{Methods of traffic decongestion}

\section{1 Changes to the geometry of intersections}

\subsubsection{Roundabout Alba lulia - Autogării}

As a solution to increase traffic speed in the roundabout, they have made improvements to the intersection geometry, namely:

- arm Alba Iulia (the center) were added two lanes, one of which is exclusive left turn, and the other for, right turn having a length of 50 meters;

- arm Autogarii added an exclusive right turn band;

- arm Alba Iulia (to Turnisor) was added an exclusive lane for left turn with 20 meter.
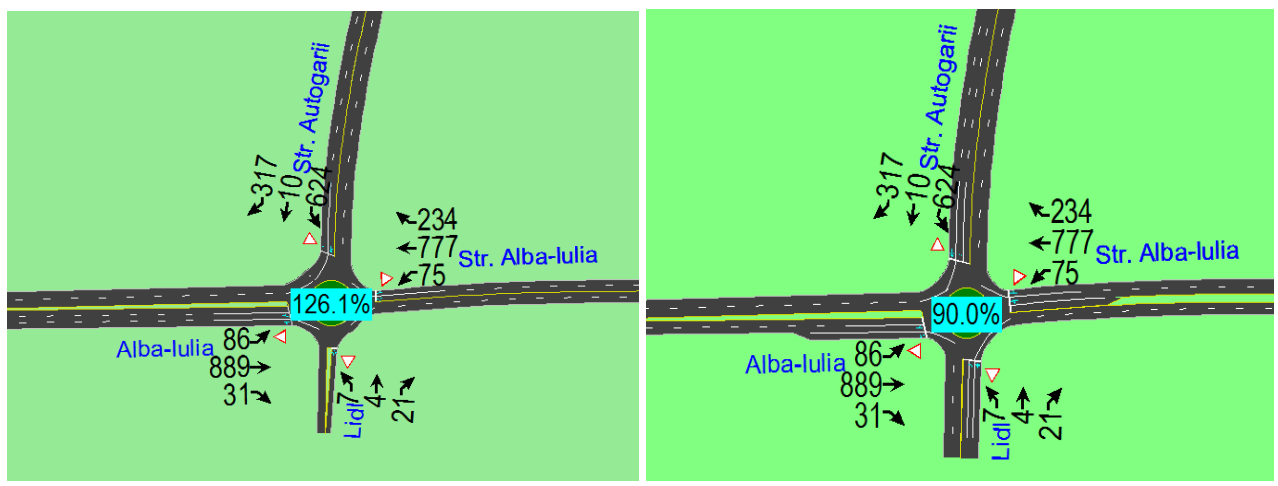

Fig. 6. Roundabout Alba Iulia - Autogării proposed solution 
As seen intersection capacity utilization rate was reduced to $90 \%$ which means that traffic flows in normal parameters, and total delay time at the intersection was reduced by cca $40 \%$ reaching from 275.6 to 164.1 seconds.

\subsubsection{Roundabout Alba Iulia - Maramureșului - Malului}

And our second roundabout noted that capacity utilization intersection exceeds $100 \%$, which means that the movement is not conducted in the normal range.
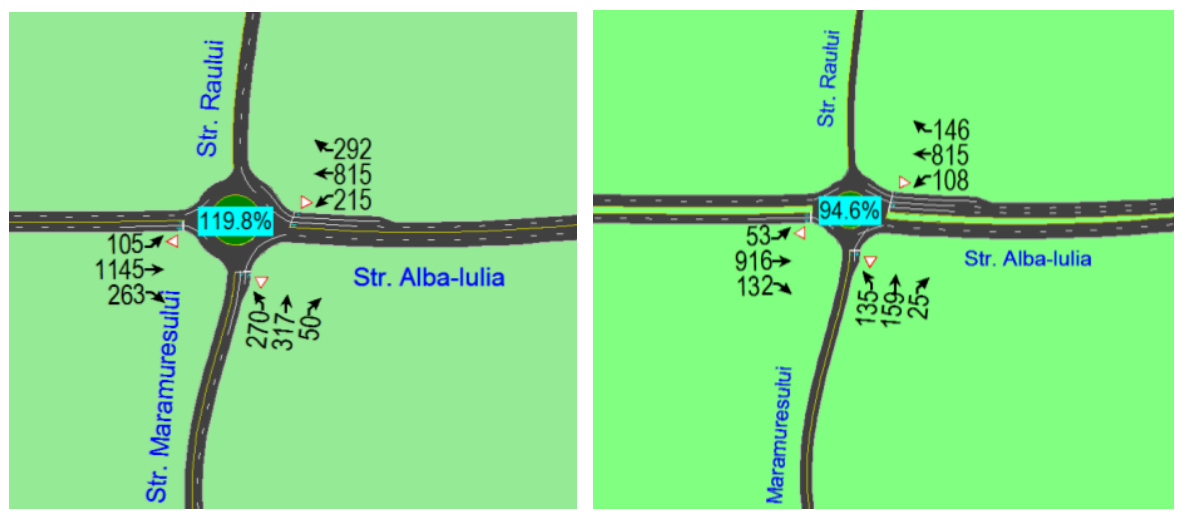

Fig. 7. Roundabout Alba Iulia - Maramureșului - Malului initial solution

And if this intersection were performed only changes the geometry and observed decrease in ICU parameter of the intersection to $94.6 \%$.

\subsection{Results}

Following the implementation of the solutions presented in section 4 were obtained results.

- Roundabout Alba Iulia - Autogării

After implementing optimization, solution is seen that the average speed of traffic on the main roads between intervals are 20 to $30 \mathrm{~km} / \mathrm{h}$ and $30-45 \mathrm{~km} / \mathrm{h}$.

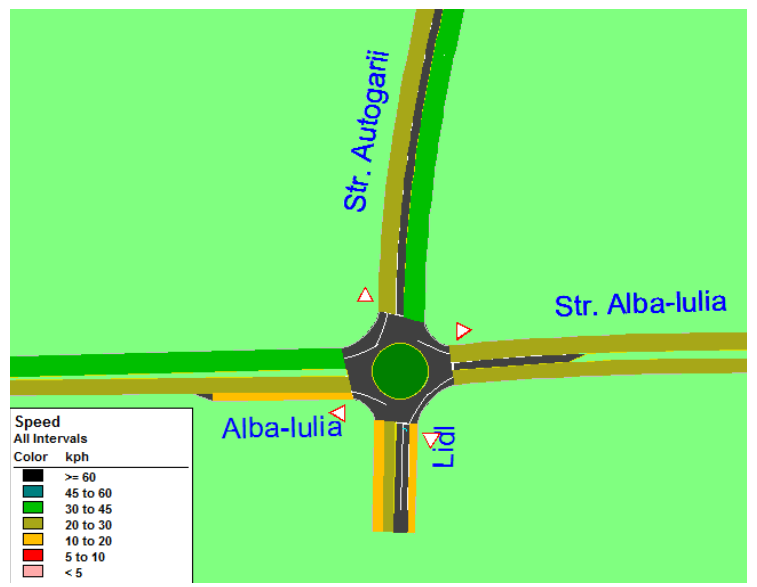

Fig. 8. Roundabout Alba Iulia - Autogării proposed solution

Speed being the smallest on the lanes from the Lidl store exit and the Autogarii is minor artery arm. 
- Roundabout Alba Iulia - Maramureșului - Malului

If the initial situation average speed of traffic on each lane was low, especially on the arm of Maramures, after implementing the solution is observed that increased velocity being between 20 to $30 \mathrm{~km} / \mathrm{h}$.

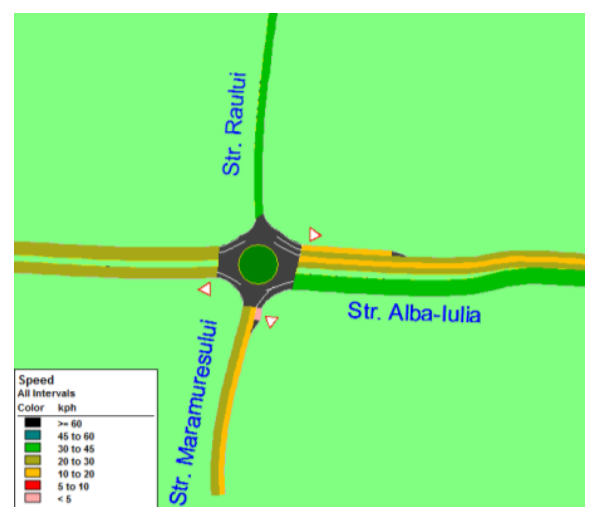

Fig. 9. Roundabout Alba Iulia - Maramureșului - Malului - the proposed situation

After geometric solutions implementations in the two intersections have reduced the number of stops and time of crossing. As disadvantage by implementing optimization, solution can not say that vehicle emissions have declined, which is higher due to increased traffic speed. hydrocarbons (HC) reached $18 \mathrm{~g}$, the carbon monoxide (CO) being $1259 \mathrm{~g}$ and the oxide of nitrogen (NOx) is $88 \mathrm{~g}$ due to the continuous flow of traffic.

\section{Conclusion}

After analyzing the data collected from the two roundabouts intersections: Alba Iulia Autogarii Road, Alba Iulia -Maramuresului - Raului road, resulted in large volumes of traffic moving toward the city center and industrial area with a low-speed, vehicles having frequent stops and starts, forming queues along the section.

It was concluded from the analysis and simulations performed Synchro that and pedestrian traffic around intersections influence in a considerable way, because in the area shopping centers are located.

Simtraffic software confirmed the results of calculations performed in the two junctions, which resulted in implementing simulation geometric changes. Following the simulation its implementation, improvement was observed in the range of peak hours' traffic, reducing queues and delays the vehicle stops. What has not been modified fuel efficiency, which has kept the value in both cases.

The results demonstrated that the proposed solution increases the average speed of traffic, reduce queues descongesting traffic, leading to a better development of it, but they could see a downside such as emissions made by vehicles, which increased.

\section{References}

1. www.recensamantromania.ro/wp-content/uploads/2013/07/sR_Tab_8.xls (accessed 20.10.2016)

2. Federal Highway Administration, Manual of Uniform Traffic Control Devices for Street and Highways, https://mutcd.fhwa.dot.gov/pdfs/2009/mutcd2009edition.pdf (2009)

3. R. Dowling, A. Kittelson. Transportation Research Board 447 (2013)

4. http://trafficware.infopop.cc/eve/forums/a/frm/f/9767036316, (accessed 04.01.2017) 